Juda arbeitet heraus, daß Bilateralismus und das System der geschlossenen Konferenzen nicht - wie von Kritikern behauptet wird - notwendigerweise zu höheren Frachtraten und damit Verteuerung der Importe und Exporte führen müssen. Auch die multinationale Regelung des Linienkodexes könnte zu rationellerem Transport bei Preisen, die den Verladern und den Reedern gerecht werden, führen. Für die USA hätte der Linienkodex höheren Flaggenanteil und somit bessere Auslastung der amerikanischen Schiffe im Verkehr mit der Dritten Welt zur Folge. Juda empfiehlt den USA, dem Kodex in Anlehnung an die "Brussels Package" beizutreten. Dies würde den USA Vorteile bringen und sie aus der derzeitigen Isolierung herausführen.

Juda's Buch stellt eine kritische Bestandsaufnahme amerikanischer Schiffahrtspolitik dar; es reflektiert die Widersprüche der verschiedenen Konzeptionen der Carter- und Reagan-Administration. Juda appelliert an die maritime Industrie und die Regierung, den Veränderungen in der Weltschiffahrt Rechnung zu tragen und Vormachtbestrebungen auf zugeben.

Robert Kappel

\title{
Terence Prittie
}

\section{Wem gehört Jerusalem?}

Klett-Cotta, Stuttgart, 1982, 285 S., DM 32,-

(a.d. Englischen, Whose Jerusalem?) Verlag Frederick Muller Ltd., London 1981

Die im Titel dieses Buches gestellte Frage kennzeichnet eines der Kernprobleme des Nahostkonflikts. Eine alle zufriedenstellende Antwort zu finden, erscheint unmöglich; auch Prittie ist dies nicht gelungen.

Schon im 1. Kapitel, in dem der Autor Situation und Probleme Jerusalems beschreibt, wird deutlich, daß seine Sympathien Israel gelten; insbesondere gibt er seine fast vorbehaltlose Bewunderung Teddy Kolleks, des Jerusalemer Bürgermeisters, zu erkennen. Die sehr subjektive Sicht, die in der einseitigen Auswahl und Darstellung der Geschehnisse zum Ausdruck kommt, muß vielfach zum Widerspruch reizen, andererseits nimmt man Prittie aber sein großes Engagement und seine Liebe zu dieser Stadt ab; es ist ohnehin fraglich, ob ein so emotionsbelastetes Thema einer objektiven Darstellung zugänglich ist.

Prittie geht zunächst auf die wechselvolle Geschichte Jerusalems ein, wobei er sein besonderes Augenmerk auf die Entwicklung des jüdischen Bevölkerungsanteils der Stadt richtet. Er betont die besondere Bindung der Juden an Jerusalem, die aufgrund der einzigartigen Verbindung von Religion, Volk und Geschichte stärker sei als die Beziehung von Christen und Moslems zu ihren heiligen Stätten in der Stadt. Ausführlich stellt der Autor die Teilung der Stadt von 1952 bis 1967 dar sowie Eroberung und Wiedervereinigung Jerusalems durch die Israelis im 6-Tage-Krieg. Die Ursache hierfür sieht 
Prittie im Verhalten Jordaniens, das sich von Nasser trotz aller Friedensangebote Israels zum Angriff habe verleiten lassen. Für die Israelis sei die Wiedergewinnung Jerusalems ein unerwartetes und endgültiges Geschenk Gottes gewesen.

Nachdem Israel die einzigartige Verantwortung über Jerusalem "auferlegt" worden war, habe es sich ihrer würdig erwiesen. Trotz einiger Vorbehalte hätten die Israelis eine sehr rücksichtsvolle Religionspolitik betrieben, freien Zugang zu den heiligen Stätten gewährt, viel für die Erhaltung von Baudenkmälern und Gotteshäusern aller Konfessionen getan und den Moslems die Selbstverwaltung über den Tempelberg gewährt. All dies unterscheide sich positiv von der vorhergehenden Herrschaft Jordaniens über Ost-Jerusalem. Lob verdiene auch die israelische Kommunalverwaltung. Jerusalem sei zu einer modernen, lebensfähigen Stadt ausgebaut, die Infrastruktur sei erheblich verbessert worden, trotzdem sei der Charakter der Stadt gewahrt geblieben; auch habe eine nennenswerte Diskriminierung der arabischen Bevölkerung nicht stattgefunden. Deren Vorwürfe wären zwar teilweise verständlich, aber grundlos. Prittie führt viele Mißstände auf die mangelnde Kooperationsbereitschaft der arabischen Bevölkerung zurück, die ihrerseits durch die unversöhnliche Haltung der arabischen Staaten und die Israel-Feindlichkeit vieler anderer (einschließlich der EG-) Staaten zu erklären sei.

Prittie betont die Bedeutung der Jerusalem-Frage für den ganzen Nahostkonflikt und diskutiert mehrere Lösungsvorschläge. Dabei lehnt er jede Internationalisierung oder Teilung der Stadt kategorisch ab. Stattdessen befürwortet er den auf den ehemaligen stellvertretenden Jerusalemer Bürgermeister Benvenisti zurückgehenden Vorschlag von weitgehend autonomen Stadtteilen, sog. boroughs nach dem Vorbild Groß-Londons, allerdings unter israelischer Hoheit. Dies wäre zwar keine Patentlösung, eine solche sei aber auch gar nicht möglich. Es müßten vielmehr viele kleine Schritte in Richtung auf ein besseres Zusammenleben der Menschen unternommen werden. Als Endziel schwebt Prittie offenbar eine Art Benelux-System zwischen Israel, Jordanien und einer palästinensischen "Einheit" vor, wobei Jerusalem gleichzeitig Israels Hauptstadt und palästinensischer Regierungssitz sein könne.

Ob diese Vorschläge realistisch sind, wie der Verlag im Klappentext meint, scheint zweif elhaft, zumal Prittie jede Verhandlung mit der PLO ausschließt. Er macht jedoch viele Probleme deutlich, vermittelt den Standpunkt der Beteiligten und veranschaulicht insbesondere die Interessen, die für die Israelis auf dem Spiel stehen; für die arabische Sichtweise wird man andere Darstellungen heranziehen müssen.

Martin Buchholz 